\title{
Determination of the combined vibrational and acoustic emission signature of a wind turbine gearbox and generator shaft in service as a pre-requisite for effective condition monitoring
}

\author{
Slim Soua ${ }^{1}$, Paul Van Lieshout ${ }^{2}$, Asanka Perera ${ }^{3}$, Tat-Hean Gan ${ }^{1}$, and Bryan Bridge ${ }^{1}$ \\ ${ }^{1}$ NDT Group, TWI, Granta Park, Great Abington, Cambridge, UK, CB216AL \\ ${ }^{2}$ SKM, 156 Pilgrim Street, Newcastle Upon Tyne. NE1 6SU \\ ${ }^{3}$ CMR UK, New York Industrial Park, Tyne and Wear. NE27 OQF
}

\section{Introduction}

$2.3 \%$ of the world's electric power supply is provided by wind farms. Rapid increases in the construction of wind power farms are taking place worldwide, in the highest proposed growth scenario it is estimated that by 2020 wind power could supply $2.600 \mathrm{TWh}$, about $11.5-12.3 \%$ of global electricity supply, rising to $21.8 \%$ by 2030 [1, 2 and 3]. It is expected that with this new technology structural problems will arise in wind turbine operation that will require vigilance in maintenance activities, especially with the introduction of increasingly large turbines. There is naturally much current interest in the $\mathrm{CM}$ of wind turbines and the $\mathrm{CM}$ approaches $[4,5$, 6 and 7].

A useful perspective on the importance of effective wind turbine CM is provided from a concise life cycle wind energy costing in a report by the National Wind Coordinating Committee (NWCC) [8 and 9]. Amortisation of the capital cost over 20-30 years results in a cost per annum of 70\% and of the total annual costs with operation and maintenance (O\&M) accounting for $30 \%$. The O\&M costs divide into unscheduled maintenance costs caused by unexpected component failure $(16 \%)$, scheduled maintenance $(4.1 \%)$ major scheduled overhaul $(0.92 \%)$ and other operating costs $(8.9 \%)$. The maintenance costs thus account for $21 \%$ of the total power annum costs and the unscheduled maintenance accounts account for $75 \%$ of these costs. This result should be interpreted as a life cycle average and there will be lower than average unscheduled costs in some years and higher in others. It is estimated the replacement of components in planned repairs during scheduled maintenance downtime costs only $43 \%$ of the cost of repairs on failure [10].

The approach taken in this work is to combine Accelerometers and AE sensors data, a method that has never been reported before for wind turbine [11, 12 and 13]. Jointly these sensors can detect the entire spectrum of vibrational frequencies that are likely to be generated in the operation of a wind turbine gearbox and the generator slip ring.

\section{Monitoring of wind turbine gearboxes: case histories}

For the numerous components in a wind turbine Figure 1 shows the malfunction rate as a percentage of the total number of malfunctions $[15,16]$ and the corresponding down time as a percentage of the total downtime [13]. This data shows that whilst the turbine gearbox, generator and main shaft/bearing and gearbox account for only $10 \%$ of the malfunctions they result in $53 \%$ of the total downtime.

\section{Data Acquisition}

The CM system developed in this work is required to be capable of distinguishing different deterioration modes and of providing data from which estimation of the time to failure can be evaluated. The $300 \mathrm{~kW}$ wind turbine dedicated to the testing was provided by Sinclair Knight Merz (SKM) for the BearInspect project [7]. As reported by SKM the rotational speed range of shafts in the $300 \mathrm{~kW}$ windmaster (Figure 1) provided for the test is up to $1500 \mathrm{rpm}$.

\subsection{Accelerometer and $\mathrm{AE}$ sensors}

The location of the sensors and the data acquisition equipment on the wind turbine are shown in Figures 2, 3a and b. Accelerometer No 1 and AE sensor No 1 located on the gearbox casing whilst accelerometer No 2 and $\mathrm{AE}$ sensor No 2 are located on the generator casing near the high-speed shaft, which transmits mechanical power into electrical power. The accelerometers (Sensonics Model P293-48H002) had output sensitivities of $100 \mathrm{Mv} / \mathrm{g}$ over $0.4 \mathrm{~Hz}-11 \mathrm{kHz}$ to better than $3 \mathrm{~dB}$, and the AE Sensors (Vallen Model VS900-RIC) had sensitivities exceeding $100 \mu \mathrm{V} / \mu \mathrm{bar}$ over the range $100 \mathrm{kHz}-950 \mathrm{kHz}$, with a peak $22 \mathrm{~dB}$ higher at $350 \mathrm{kHz}$. 


\subsection{Wind speed and power measurements}

The principal operation is based on the timeline shown in Figure 4. A wind speed/power measuring Logger is given a trigger to start collecting data. Therefore, the wind speed data was initially separated and according to the modulated wave signal, the wind speed was determined. The current wind speed was compared against a table representing the bins and the number of data per bins collected from a minimum of $5 \mathrm{~m} / \mathrm{s}$ to a maximum of $29.9 \mathrm{~m} / \mathrm{s}$.

\section{Overview of the current data acquisition}

\subsection{The power versus wind speed}

The operation of the CM process has resulted in 813 files (32Gbytes). The files were acquired during an overall measurement period of 5 days. The 813 files were distributed into $615 \mathrm{~kW}$ wide power bins according to the power output in the range $0-300 \mathrm{~kW}$ i.e. the data processing precision for the power measurements is effectively $+/-2.5 \mathrm{~kW}$. In Figure 5, power output as a function of wind speed is shown.

\subsection{Data processing and filtering}

A means of reducing the large amount of measurement data was necessary and the following steps were thus taken:

- A $10 \mathrm{kHz}$ to $250 \mathrm{kHz}$ band pass filter was applied to the $\mathrm{AE}$ signals which were then re-sampled from $5 \mathrm{MSa} / \mathrm{s}$ to $1 \mathrm{MSa} / \mathrm{s}$. The band pass range was chosen because most of the energy in the spectrum lies within this range, as shown in Figure 6. So restricting the filter to this range avoids unnecessary signal processing and minimises the input noise without loss of significant information.

- The flat response bandwidth of the accelerometers was limited to $0.4 \mathrm{~Hz}-11 \mathrm{kHz}$ within the $3 \mathrm{db}$ standard. Therefore, a low pass was applied to the signals, which minimised the signal processing without losing significant information.

\section{Discussion of results}

\subsection{The sensor signatures for the healthy turbine}

For all 4 sensors it can be seen that the variation of $\mathrm{V}_{\mathrm{RMS}}$ (average) with power is approximately as systematic as the power output dependence on wind speed, considered in terms of the spread of data along the signal axis at each power level (Figure 7).

\subsection{Explanation of the overall curve shapes}

\section{- On the gearbox casing}

There are rotating components that transform the input power from the hub to the shaft between the gearbox and the generator. As the wind speed varied by a factor of 5 , between $5-25 \mathrm{mph}$ in the reported measurements and the rotation speed of the generator shaft was almost constant, a range of rotational frequencies were involved with the gearbox components. Assuming a constant ratio of hub speed to wind speed, the rotational frequencies of some of the gearbox components could have varied by a factor over the considered power range. Following the frequency square law, sensor responses from any rotating circumferential defects in the gear could thus vary over the power range by a factor of 25 . As the swing in sensor responses across the power range from $50 \mathrm{~kW}$ $300 \mathrm{~kW}$ is only a factor of 2 there are clearly no significant frequency dependent effects in the sensor signals. To this extent, the gearbox signature can be considered consistent with a healthy gearbox.

\section{- On the generator casing}

As the power is increased from 0 to $300 \mathrm{~kW}$ the rotation frequency of the transmission shaft between the gearbox and generator slightly varies from 1500 from to $1530 \mathrm{rpm}$. Thus, the change in frequency squared is only $4 \%$. Taking the very approximately linear portion of the curves between $50-300 \mathrm{~kW}$ the swings in sensor signals are far higher, i.e. a factor of $\cong 2$ when averaged over the 4 data sets. So, the variation cannot be caused by the 'frequency squared' effect. Therefore, there is no evidence of the presence of defects in the rotating components, the structure being monitored can thus be declared healthy.

\section{Standard deviations and the relationship with the probability of defect detection (POD)}

The probability of detecting a defect in 1second measurement times during operation is defined by the error function assuming that Gaussian statistics apply i.e.

$$
\mathrm{POD}=\operatorname{erf}\left(\mathrm{V}_{\mathrm{RMS}}(\text { average }) / \sigma\left\{\mathrm{V}_{\mathrm{RMS}}\right\}\right)
$$


As an example, for erf (3) i.e. a defect voltage three times the healthy turbine signature voltages, the detection probability is 0.99998 . i.e a false alarm would arise only 1 time in 500001 second measurements. Therefore, there would be just one false alarm per year if 137 independent 1 second measurements were made daily.

It is useful to ascribe standard deviations to the healthy signatures, as these quantities will ultimately determine the minimum detectable defect size and their POD. For this purpose, the region between 0-50kW and between $50-300 \mathrm{~kW}$ will be discussed separately. The region between $0-50 \mathrm{~kW}$ has curves steep gradient for which the error bars are indeterminate. For the remaining power region from $50-300 \mathrm{~kW}$, the PODs form the better basis for minimising false calls in defect detection. These are shown in figure 8 for all sensors and for all bins.

From the figures data it can be seen that $\sigma\left\{\mathrm{V}_{\mathrm{RMS}}\right\}$ appears to be useful for both $\mathrm{AE}$ and vibrational monitoring; in fact the POD is high for the power region from 50-300kW (POD>erf (3)). However, for the region between $0-50 \mathrm{~kW}$, the minimum POD seems to drop down to $84 \%$ which is equivalent to erf(1.01).

\section{Signatures identification}

From the above analysis and the conclusions developed from section 5.2, the data acquired so far on the wind turbine is valid for the determination of a signature that will be used as a reference for future similarity analysis. Figure 9 shows the signature that was defined - for each sensor - taking into account a safety operation range offset of $\pm \sigma\left\{\mathrm{V}_{\mathrm{RMS}}\right\}$.

The POD is found to be high especially at high power/wind speed, which implies high discrimination of defects -in case they appear- which will be unlikely to generate false alarms.

\section{Conclusions}

First measurements on the in service acquisition of the vibration and AE signature of a healthy wind turbine generator and gearbox have been presented. The standard deviations for the averaging of the time dependent sensor signals, namely $\sigma\left\{\mathrm{V}_{\mathrm{RMS}}\right\}$ and the PODs, has been calculated. These quantities represent the uncertainty in the healthy turbine and they determine the minimum detectible defect size.

This result forms an excellent basis for the development of an Alarm based CM process for wind turbines usable over the entire power operational range.

Future work is required to develop similarity analysis based on the Euclidian distance in order to evaluate similarities between the signature and future monitoring data (figure 10).

\section{Acknowledgements}

The authors gratefully acknowledge the financial support of the UK Northern Wind Innovation Program NWIP.

\section{References}

[1] Global Wind Energy Outlook 2010, Global Wind Energy Council (GWEC) October 2010, page 10.

[2] Ibid page 50.

[3] Ibid page 14.

[4] A Kusiak and W Li 'The prediction and diagnosis of wind turbine faults' Renewable Energy 36 (2011) 16-23.

[5] Z Tian, T Jin and B Wu et al 'Condition based maintenance optimisation for wind power generation systems under continuous monitoring, Renewable Energy, 36, Issue 5, May 2011, 1502-1509.

[6] G. M. Joselin Herbert, S. Iniyan and R Goic, Performance, reliability, and failure analysis of wind farm in a developing country, Renewable Energy, 35 (2010) 2739-2751.

[7] www.bearinspect.com

[8] Wind Energy Costs January 1997 No 11 Wind Energy Issue Brief, National Wind Coordinating Committee.

[9] http://www.bwea.com/ref/faq.html renewable UK The voice of wind and marine energy, accessed 01/02/2011.

[10] Rolf F Orsagh, Hyungdae Lee and Jon Powers 'Advanced vibration monitoring for wind turbine health management' ibid.

[11] Slim Soua, Laurent Cebulski, Tat Hean Gan and Bryan Bridge. On Line Monitoring of a Power Slip Ring on the Shaft of a wind power generator. Insight 53 | Issue: 6, June 2011, pp 321-329.

[12] Slim Soua, Bryan Bridge, Laurent Cebulski and Tat-Hean Gan Statistical analysis and modelling of accelerometer data in the on line monitoring of a power slip ring in a wind turbine. Accepted for publication at Measurement Science and Technology (IOP) December 2011.

[13] D Mc Millan and G. W. Ault 'Quantification of condition monitoring benefit for offshore wind turbines, Wind Engineering Vol 31, No 42007. 
[14] Chia Chen Ciang, Jung-Ryual Lee and Hyung-Joon Bang 'Structural Health monitoring for a wind turbine system: a review of damage detection methods' Meas.Sci. Technol, 19 (2008) 122001 (20pp).

[15] B. Hahn, m. Durstewitz and K Rohrig, 'Wind Energy, (Reliability of Wind Turbine Experiences of 15 years with 1,500W), ED j Pienke et al (Berli: Springer) pp 329-32 2007.

[16] Steve Barber and P. Golbeck, 'Wind Turbine Maintenance and Condition Monitoring WindRisk Canada, Windrisksolutions.com, http://www.wwindea.org/techlogy/ch03/en/3_4_3.html. 
Unforeseen malfunction as a percentage of the total turbine malfunction. Data adapted from

[13]. Absolute downtimes vary in the range 7.5-15 days between different wind farms.

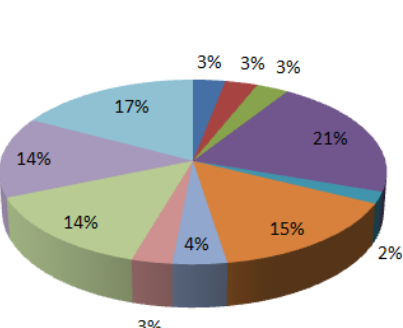

$3 \%$
- Electrical system

- Sensors

- Plant control system

- Gearbox

- Mechanical break

= Main-shaft/bearing

$\varpi$ Hydraulic system

- Yaw system

Rotor hub

- Rotor blades

m Generator
Unforeseen malfunction as a percentage of the total turbine malfunction. Data adapted from

$[15,16]$. Absolute downtimes vary in the range $7.5-15$ days between different wind farms.

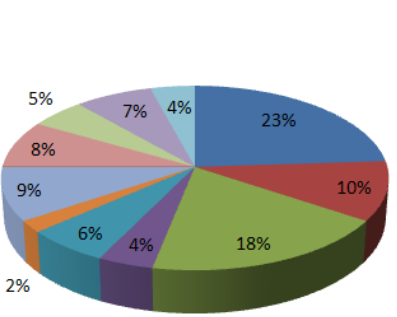

Electrical system

u Sensors

I Plant control system

- Gearbox

- Mechanical break

Main-shaft bearing

- Hydraulic system

In Yaw system

- Rotor hub

- Rotor blades

॥ Generator

Figure 1. Wind turbines malfunction incidents and downtime 


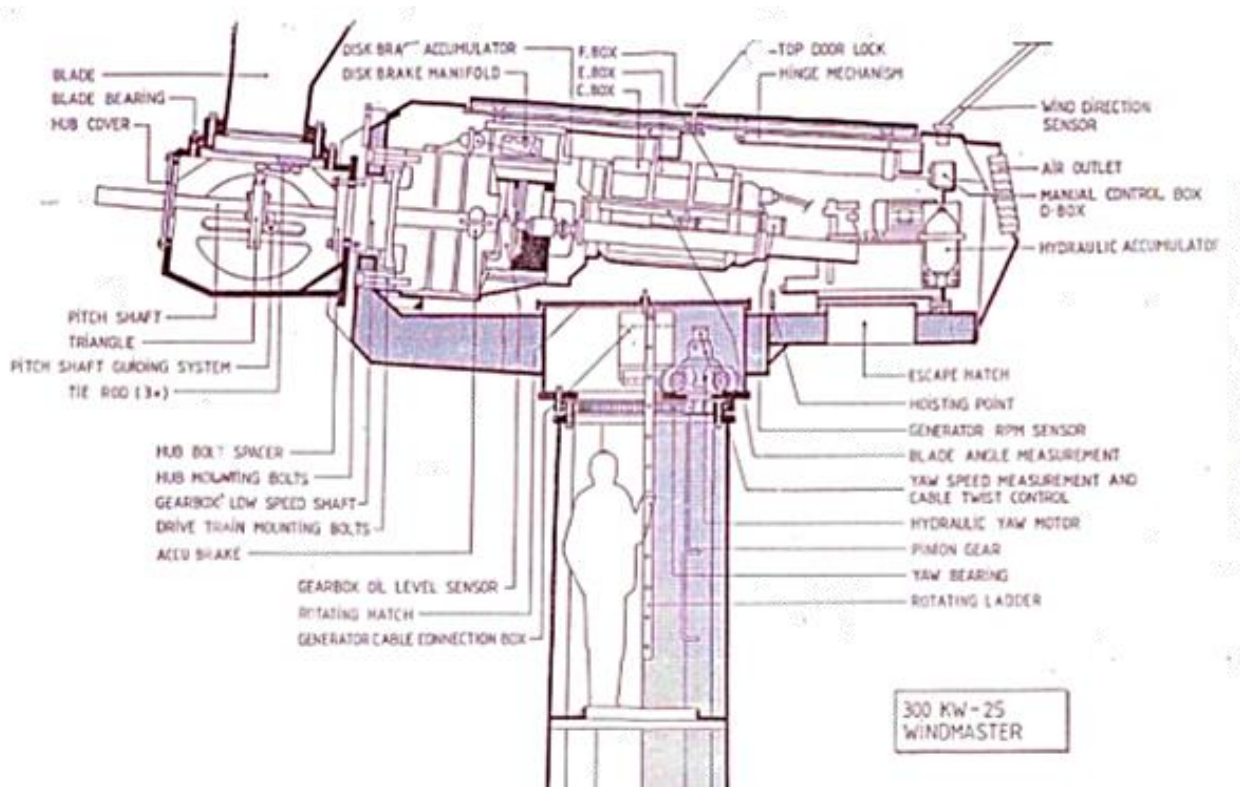

Figure 2. Sketch of the entire wind turbine. 


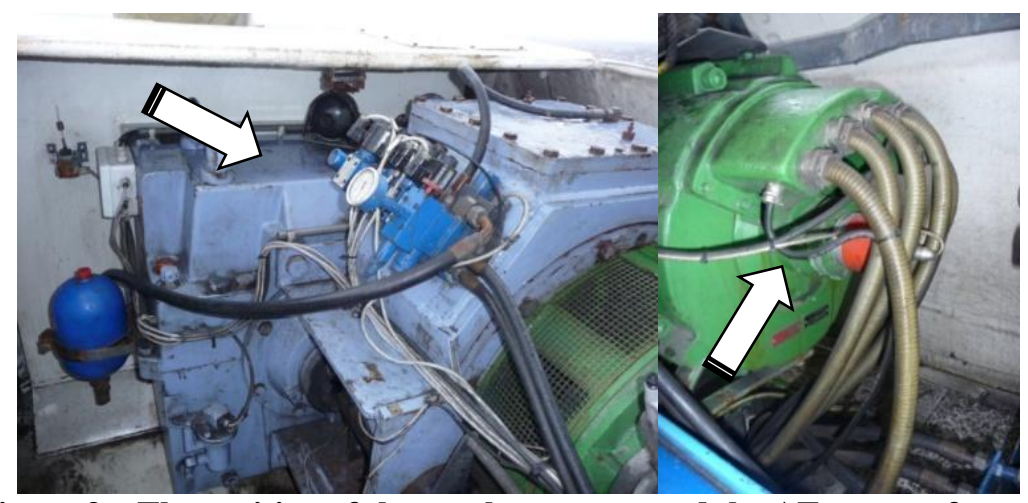

Figure 3a. The position of the accelerometers and the AE sensors for: a. the gearbox and $\mathrm{b}$. the generator. 



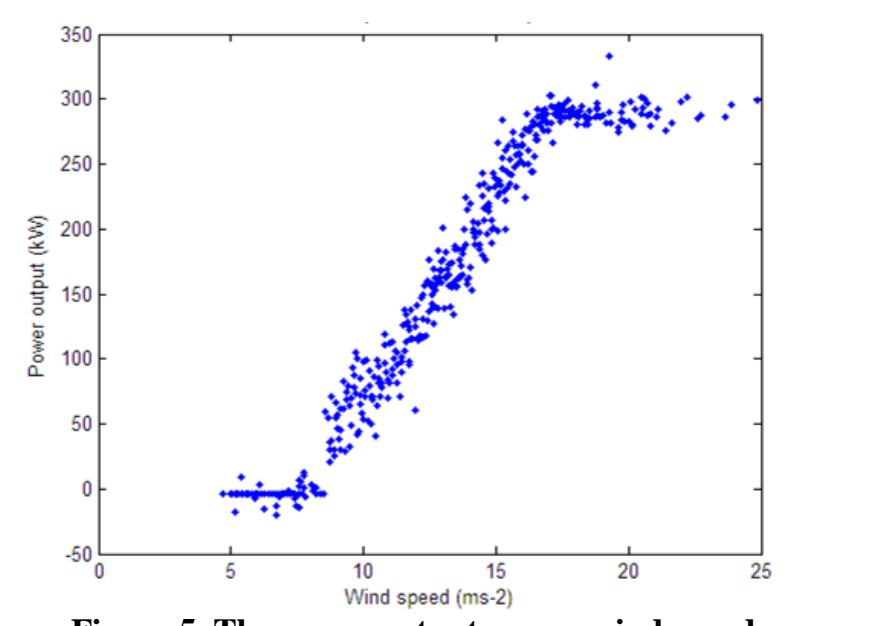

Figure5

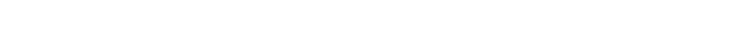

Figure5 


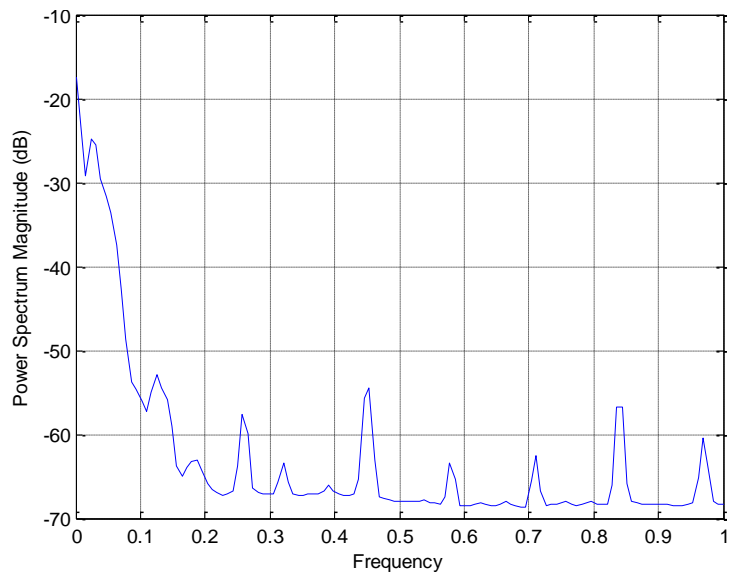

Figure 6. Typical PSD of the AE vs normalised frequencies. 

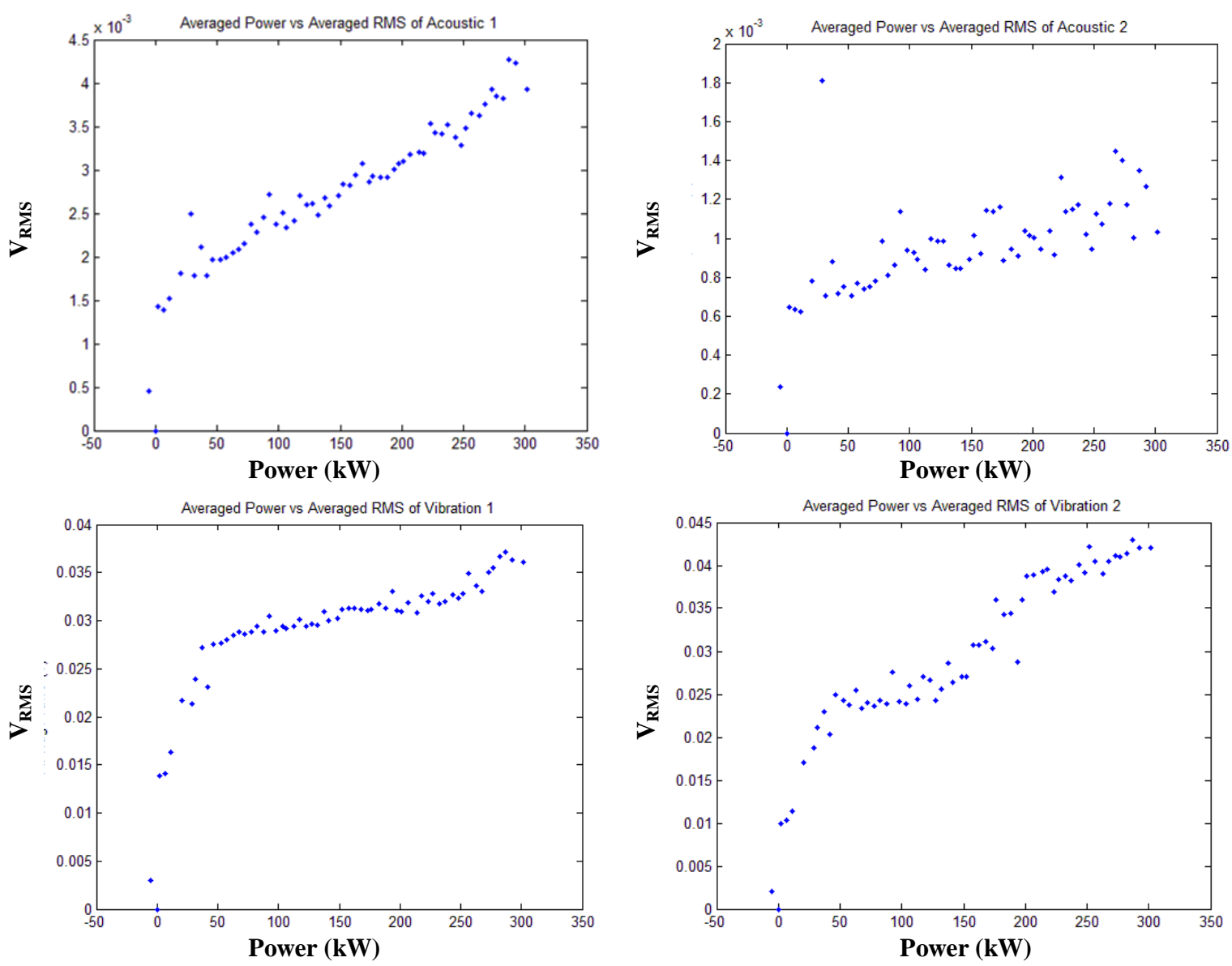

Figure 7. Dependence of RMS voltage versus power 

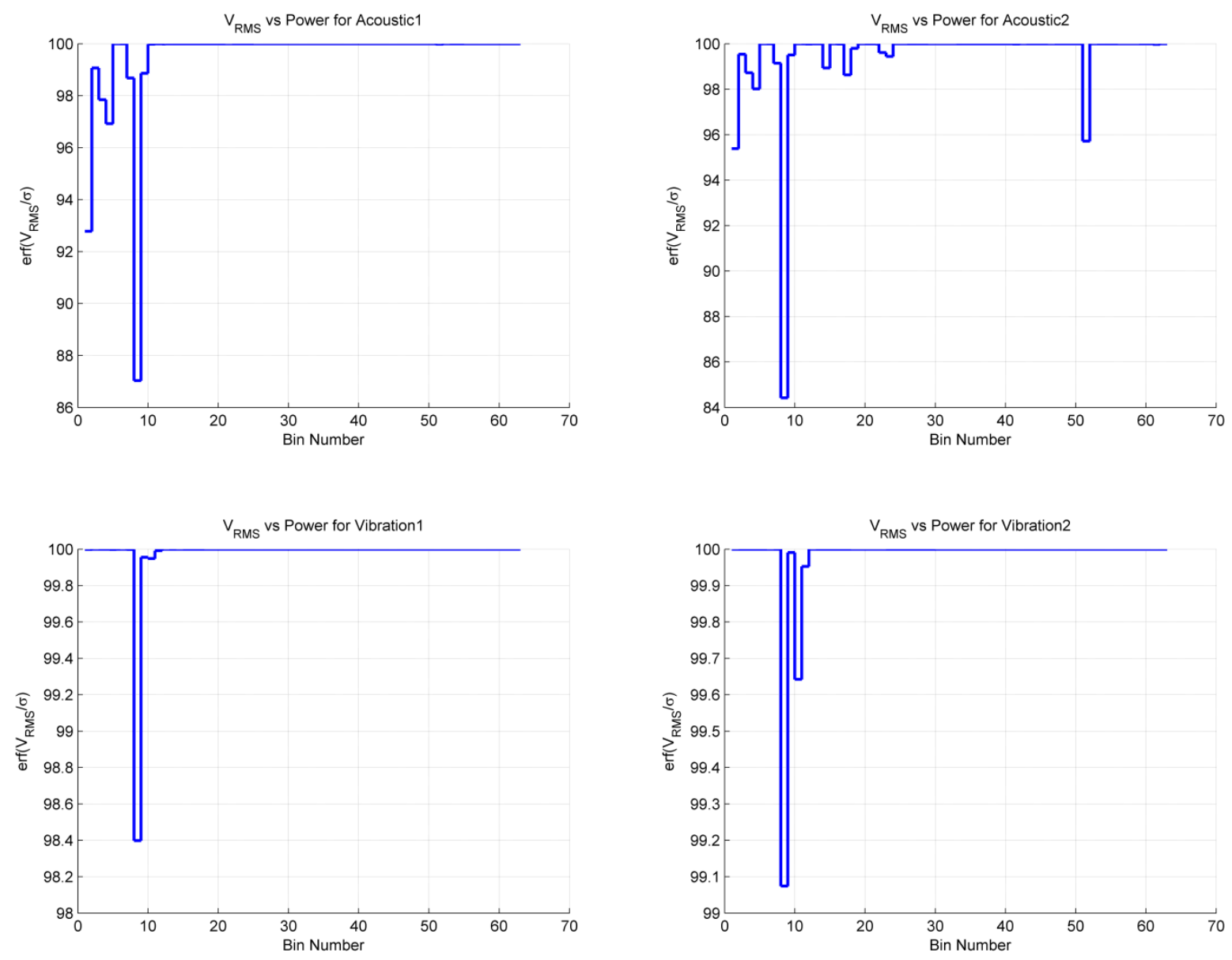

Figure 8. POD based on the Gaussian Error function erf $\left(\mathbf{V}_{\mathbf{R M S}}(\right.$ average $\left.) / \sigma\left(\mathbf{V}_{\mathbf{R M S}}\right)\right)$ 

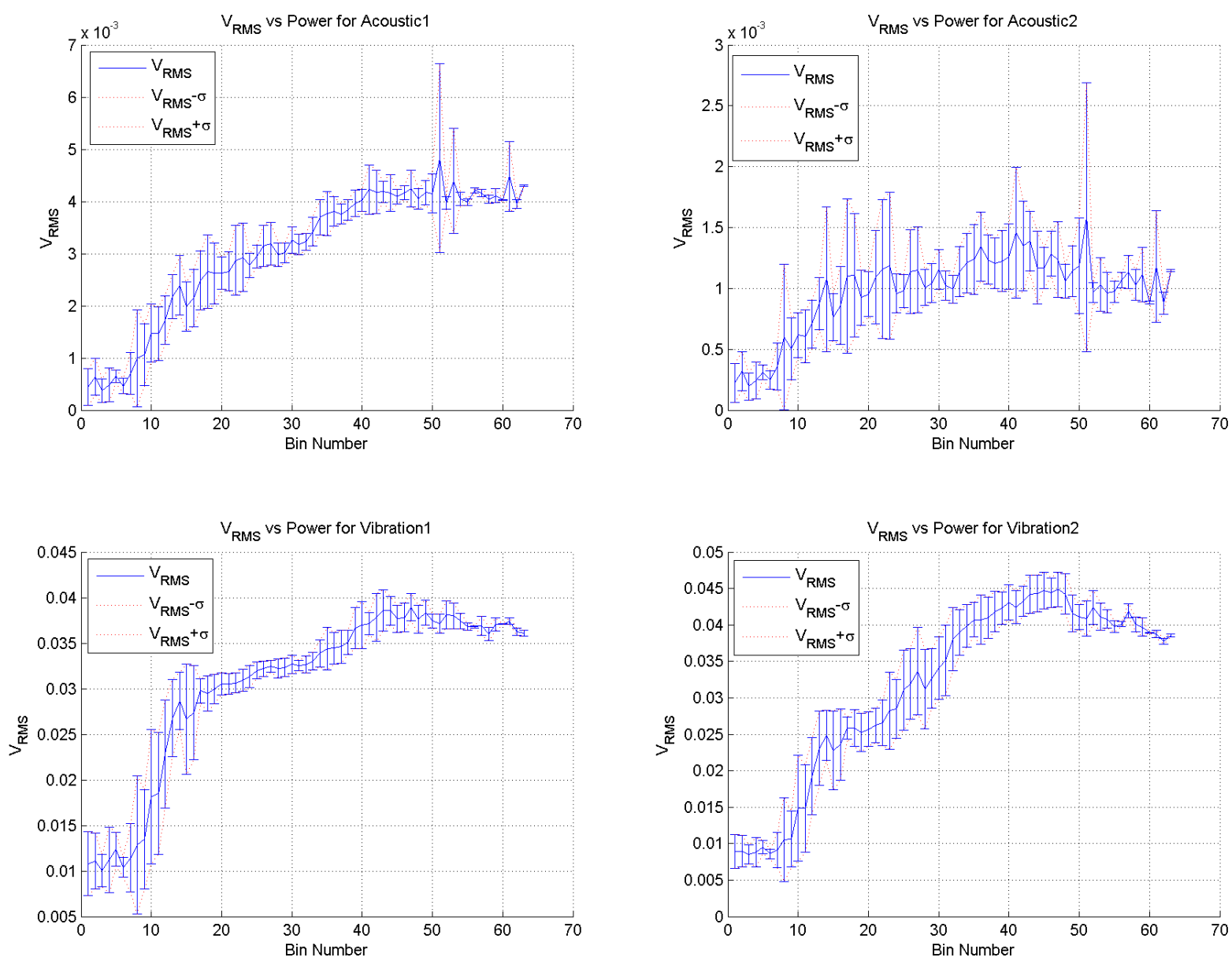

Figure 9. The signatures for safety range offset of $\pm \sigma\left\{V_{\text {RMS }}\right\}$. 


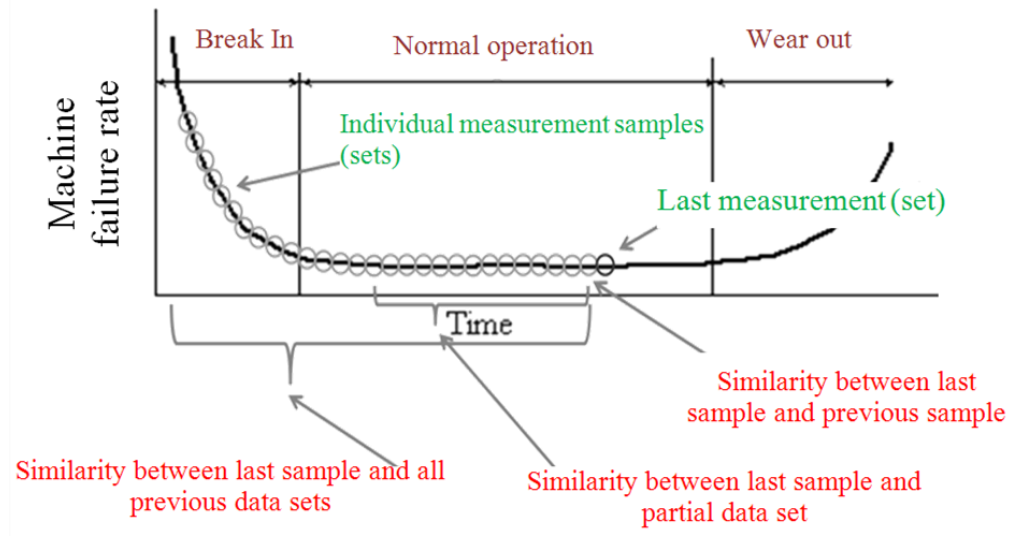

Figure 10: Variation of the operational state of a machine judged in terms of the variation of failure rate during the machine design life. 